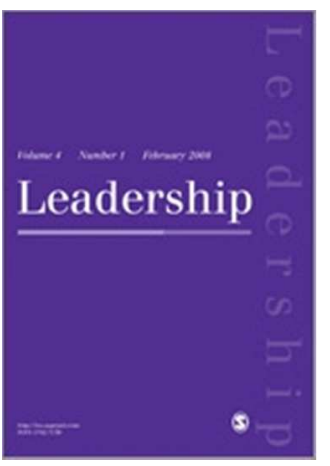

\title{
The power of positioning: how leadership work unfolds in team interactions
}

\begin{tabular}{|r|l|}
\hline Journal: & Leadership \\
\hline Manuscript ID & LEA-17-0178.R2 \\
\hline Manuscript Type: & Standard Article \\
\hline Keywords: & $\begin{array}{l}\text { Discursive leadership, Positioning, Ethnography, Research team, } \\
\text { Ethnomethodology }\end{array}$ \\
\hline Abstract: & $\begin{array}{l}\text { Drawing on literature conceptualising leadership as a discursive } \\
\text { accomplishment, this paper defines leadership as leadership work: a } \\
\text { process unfolding through talk, and depending on a unique dynamic among } \\
\text { the resources that participants bring to an interaction, and the ability of the } \\
\text { participants to creatively mobilise these resources to perform the task at } \\
\text { hand. Leadership work can be understood through the analysis of how } \\
\text { individuals position themselves and others in an interaction. Data from an } \\
\text { ethnographic study of an academic research team support our arguments. } \\
\text { The paper contributes to the literature on leadership as a process by } \\
\text { demonstrating that positioning is not only necessary for leadership to } \\
\text { unfold, but it also allows a more nuanced analysis of leadership work, by } \\
\text { opening researchers' eyes to the variety of resources involved in this } \\
\text { process. }\end{array}$ \\
\hline
\end{tabular}




\section{THE POWER OF POSITIONING: HOW LEADERSHIP WORK UNFOLDS IN TEAM INTERACTIONS}

\section{INTRODUCTION}

This paper shows how positioning theory enlightens the dynamic of power and influence which is believed to be constitutive of leadership and the kind of resources that individuals can mobilise to do leadership. As summarised by Gronn (2000: 319), most of the literature on leadership emphasises the 'belief in the power of the one'; this is known also as leadership psychology (Fairhurst, 2007) or heroic leadership (Yukl, 1999), all of which privilege the study of an individual leader's exceptional traits. Recent literature agrees that mainstream approaches to leadership prescribe a division of labour that does not reflect mundane organisational work (Gronn, 2002; Carroll et al., 2008; Kelly et al., 2006) and fail to recognise that leadership is a fuzzy concept that depends on the activities that people perform (Kelly, 2008; Denis et al., 2010). Mainstream approaches also tend to ignore the context of interaction, particularly the broader (political) effects of individuals' interpretations and their connection to social structures (Collinson, 2005; Alvesson and Sveningsson, 2003b); and impose categories which are foreign to research participants (Clifton, 2006; Huxham and Vangen, 2000). These problems are reflected in the paucity of studies that use data based on observations of daily organisational activities (Smith et al., 2017; Vine et al., 2008). Thus, there is a limited understanding of how leadership is accomplished, independently of formal roles and attributes. At the same time, leadership research seems mired in debates of legitimacy (Alvesson, 2017).

This paper returns the focus to mundane organisational activities, by looking at interactions first, and trying to understand how leadership emerges in the course of interactions. Thus, the paper is situated in the research stream inspired by discourse analysis, especially ethnomethodology, to understand how leadership is accomplished in situ (Fairhurst, 2011; 
Vine et al., 2008; Clifton, 2006; Clifton, 2012; Clifton, 2017; Larsson, 2016; Larsson and Lundholm, 2010; Choi and Schnurr, 2014; Van De Mieroop and Schnurr, 2014; Fairhurst and Uhl-Bien, 2012).

This paper defines leadership as 'leadership work': a process that unfolds through talk, and depends on a unique dynamic between personal and social resources that participants bring in an interaction, and the ability to creatively mobilise these resources to perform a task. Leadership work is made possible by positioning: this is the reciprocal construction of participants' positions in an interaction, which is capable of shaping power relations in an interaction (Wiggins and Potter, 2008; Harré and Van Langenhove, 1998; Edwards and Potter, 1992; Davies and Harré, 1990). Barge and Fairhurst (2008) claim that positioning is especially relevant when studying leadership; however, empirical research building on this is still rare. In this paper, ethnographic data presenting a team's interactions demonstrate how leadership work unfolds in mundane organisational activities through positioning.

This paper advances the debate on leadership as a discursive process by demonstrating that positioning helps to investigate the ways in which emergent and structural resources intertwine to create different leadership constellations, and eventually enhance our understanding of leadership itself. Thus, the paper builds on Schnurr and Schroeder (2018) call to leadership scholars for a deeper engagement with applied linguistics and pragmatics, Larsson's (2016) recommendation to connect empirical analysis with conceptual issues in leadership theory, and Tourish's (2014) argument to study the emergence of leadership through discourse.

\section{LEADERSHIP WORK AS A DISCURSIVE PROCESS}

Using existing literature, a conceptual framework is built to assist in the study of leadership as 'leadership work'. Leadership work unfolds through talk and depends on a unique dynamic among resources that participants bring in an interaction. It also entails the ability to use these 
resources strategically to perform the task(s) at hand. This framework links leadership with mundane organisational activities and events, and especially with processes of positioning. It also stresses that leadership is an emergent and open process, depending simultaneously on stable arrangements (i.e. social and personal resources that people bring to an interaction, including their formal and informal roles) and highly contextual conditions (i.e. the task at hand and how this is managed by participants in an interaction). The distinction between personal and social resources is an analytical one, since we expect links between the two.

'Leadership work' weaves together several perspectives on human interaction and leadership: ethnomethodology (Garfinkel, 1967), especially the way in which participants in an interaction build and give meaning to their world; discursive leadership (Fairhurst, 2007; Fairhurst, 2008), which highlights the importance of how actors advance specific activities for building leadership; and leadership as a process, which stresses the need to suspend categorising the world (i.e. leaders and followers) to embrace the highly contextual and constantly unfolding nature of leadership (Wood and Ladkin, 2008; Uhl-Bien, 2006). Putting these perspectives into communication is not new: following Fairhurst and Uhl-Bien (2012), ethnomethodology is an important approach for analysing discursive leadership. Schnurr and Schroeder (2018) argue that leadership studies would benefit from a deeper engagement with applied linguistics and pragmatics, two disciplines that have benefited from ethnomethodology.

The first studies investigating interactions in specific organisational contexts, and how participants in an interaction construct their world, were inspired by ethnomethodology (Boden and Zimmerman, 1991). Conversation analysis, which is the approach for ethnomethodologists to study interactions (Sacks et al., 1974; Drew and Heritage, 1992), inspired the first research on business meetings (Schwartzman, 1989; Boden, 1994; Huisman, 2001; Asmuß and Svennevig, 2009; Svennevig, 2008; Svennevig, 2012). This literature has 
highlighted some patterns of talk and their implications for the development of an interaction; for example, it helped to reveal how participants in an interaction claim membership to specific categories (e.g., team leader) as a way of claiming some privilege in that interaction (Sacks, 1992; Stokoe, 2012). Thus, ethnomethodology causes scholars to look at human interaction from an emic perspective (i.e. of actors): this means understanding how participants in an interaction jointly negotiate what is relevant for them at that moment. Such an approach to the study of human interaction would significantly help to achieve a more nuanced understanding of how leadership happens, and to resolve the debate on the meaning of leadership as a category of study (Alvesson and Sveningsson, 2003a; Larsson, 2016; Gronn, 2000; Kelly, 2014). However, leadership literature inspired by ethnomethodology is still limited (Clifton, 2017; Schnurr and Schroeder, 2018). This paper therefore concentrates on what we can learn by looking at interactions first, and by proposing a method to investigate leadership work. This is the analysis of positioning, which constitutes the novelty of this contribution.

\section{LEADERSHIP WORK AND POSITIONING}

Positioning is related to what participants in a conversation do in real time. Davies and Harré (1990: 48) define it as:

the discursive process whereby selves are located in conversations as observably and subjectively coherent participants in jointly produced story lines. There can be interactive positioning in which what one person says positions another. And there can be reflexive positioning in which one positions oneself.

Harré and Van Langenhove (1998) explain that positioning affects the negotiation of rights and obligations of speaking and acting in a conversation; the process of negotiating rights and obligations in a conversation allows participants to establish a moral order, which is local (i.e. situated) and open to change (Harré et al., 2009). In addition, positioning might be performative (it has immediate effects on activities) or accountive (people might be forced to 
take or reflect on their positions). Importantly, people can intentionally draw on their resources (i.e. discursive and social skills) to work on positioning. Each participant in an interaction has his or her own sets of resources, priorities, and power, built into former episodes: a single episode is part of a storyline, and participants orient to identities that affect the positioning processes.

The concept of positioning is widely used in narrative studies on identity work (Deppermann, 2015). Positioning has been advocated as a key concept to study how identities unfold in talk and how it might be crafted to the audience (Bamberg and Georgakopoulou, 2008; Van De Mieroop and Schnurr, 2014; Bamberg, 1997). However, there are important critiques, especially regarding the concept of storyline. Deppermann (2015) argues this seems to refer to some sort of rigid macro-structure. In contrast, Clifton (2014) argues that positioning allows analysis that involves both little-d and big-D discourse, referring to the two typologies as defined in by Alvesson and Kärreman (2000). This paper agrees with Heritage and Clayman's (2011) stance, influenced by ethnomethodology, that what is considered to be structure is relevant as long as the participants bring it into the discussion.

This paper argues that the analysis of how individuals position each other in an interaction reveals how leadership work emerges. Thanks to positioning, one or more participants can take the lead in performing tasks that are relevant to them and influence other patterns that are associated with leadership (Fairhurst, 2007; Hosking, 1988; Gronn, 2002; Robinson, 2001; Fairhurst and Connaughton, 2014); this might change with participants' position or when they engage in accountive positioning, implying that leadership work is an open-ended process. The central argument in this paper is that positioning is essential for leadership to unfold, and also, it permits a more nuanced analysis of leadership work by opening researchers' eyes to the variety of resources involved in this process. 
Barge and Fairhurst (2008) propose positioning, sensemaking, and play as processes to examine when making a systemic analysis of leadership. They state that leadership actors can shape their position within a conversation by developing reflexive abilities. So even if positioning is a joint process, participants in a conversation can consciously work on it. Barge and Fairhurst's (2008) programme has been only partially undertaken; as noted by Clifton (2017), the interest in how leadership is produced through talk is recent, since it requires a radical shift from the mainstream literature on leadership.

Crevani (2018) uses positioning to analyse a practice that she defines as central in leadership work (i.e. giving direction). However, she does not study the link between positioning and the resources each participant brings in a conversation; it follows that some configurations of power might be overlooked. Hirvonen (2016) draws on positioning to analyse decision making in team meetings; he highlights the link between leadership and positioning, especially referring to the preassigned role of chair. Choi and Schnurr (2014) and Smith and colleagues (2017) do not focus on positioning, yet their contributions are interesting because they study teams that do not present a clear line of authority. Choi and Schnurr (2014) concentrate on disagreements during meetings: they show that leadership is a conjoint process, where different individuals can take on a leadership role at different points; also, they demonstrate how the wider institutional framework impacts on the local negotiation of leadership. Smith and colleagues (2017) show that leadership revolves around the ability to make meaningful contributions for the group's identity (e.g., giving direction and reducing uncertainty). Interestingly, they stress that some leadership practices might be tied to specific identities, which arise unpredictably along an interaction; this makes difficult to understand the nature of leadership.

The most remarkable contribution is Clifton (2014) study of the use of small stories in business meetings. Clifton focuses on how some participants in an interaction 'do leadership' 
through positioning. Two points are highlighted: first, leadership is tied to a process of meaning-making in which any participant can engage through positioning; second, some of the discursive resources allowing participants to work on their positioning (e.g., opening or closing a discussion) might be category-bound to specific identities that the participants themselves bring into talk (e.g., being the more senior team member). This second point has been stressed in a previous contribution as well (Clifton 2012). More recently, Clifton (2017) has proposed focusing on the management of meaning when studying distributed leadership from a relational and discursive standpoint. Again, Clifton insists that while some leadership moves might be available to all the participants in an interaction, others might be bound to specific identities (for example, closing a discussion is a leadership strategy that might be available only to a hierarchical superior).

The review shows that, despite the paucity of literature on leadership as a discursive process, scholars emphasise two issues: (1) leadership might depend simultaneously on emergent relationships and more stable arrangements; (2) positioning helps focus on the emergent nature of leadership without dismissing the individual's resources. However, our knowledge of the resources people bring into an interaction is limited to Clifton's (2014) contribution, in which the author focuses on the discursive resources. It is necessary to consider these resources from a broader perspective: resources might be social (e.g., claiming membership to a group) and personal (e.g., individual skills and abilities). Clifton (2014) also seems to assume that the use of some resources is tied to specific identities, while here it is argued that the process might be much more fluid. These two arguments constitute an important contribution of this paper, and we will expand upon them in the presentation of the findings.

[Figure I (Conceptual framework) above here]

\section{RESEARCH DESIGN}


This paper explores how discursive leadership unfolds in the group interactions of an academic research team, by addressing two questions: (1) How do positioning processes in team meetings affect leadership work? (2) Which resources are mobilised in the positioning processes characterising leadership work?

An ethnographic study has been designed to answer the questions above; according to Sutherland (2016), ethnography has the potential to open up new understandings of leadership. Data were collected during one year of observation in a research team from an academic department of computer science in Switzerland, starting in 2010. The team consists of 10 people: a group chair, three postdoctoral researchers, and six $\mathrm{PhD}$ students. Group activities were observed. The following data were produced: observation of 23 team meetings (with video recordings and notes), two clusters of individual in-depth interviews, two group discussions, and collection of the email exchanges from the mailing list (around 280 messages). The role of the researcher has been nearer to that of an observer; however, more direct engagement occurred sometimes, especially in social activities.

Most of the observations were of team meetings, while the other data support the interpretation. Meetings take place every week during term time, are on average 1 hour and 20 minutes long, and everybody usually participates. In this paper, the analysis concentrates on a corpus of 12 meetings, following theoretical sampling (Eisenhardt, 1989). Meetings present recurrent patterns in relation to the main topics being discussed: very different issues can be raised for discussion during meetings, however, typically each meeting presents a core topic or aim (three core topics have been detected: discussing a paper; discussing one of the members' research; planning future team activities). The corpus is composed of meetings which well represent the entire dataset in terms of core topic; it amounts to more than 16 hours of recordings and around 6,400 speaking turns in the transcripts. This corpus allowed for a very nuanced understanding of leadership work, permitting saturation to be achieved. 
Following the conceptual framework, it is assumed that leadership work can be investigated by analysing how people position each other during interactions. The processes of positioning constitute the unit of analysis. This is consistent with the claim that there is the need to deflect attention from the person enacting leadership and to the leadership practice itself.

The analysis of positioning followed several steps. In a first phase, started during data collection, the researcher carefully went through the notes and the recordings of the meetings, and started transcribing to detect some patterns of interaction. Once the corpus was built, transcripts were refined and studied by focusing on positioning. Because Harré and Van Langenhove (1998) define positioning as the negotiation of rights and obligations in an interaction, transcripts were scrutinised to understand if and how each turn implies rights and obligations for specific participants. The video recordings supported this process, since bodily movements and facial expressions convey relevant meaning. Once such instances were detected, the analysis turned first to how the negotiation of rights and obligations shapes participants' positions in the discussion, to understand its impact on the achievement of the task at hand. It then examined the kind of resources that participants invoke to support their position. These two steps allow observation of how leadership work is shaped. The analytical process is exemplified in figure II.

[Figure II (Analytical framework) above here]

\section{RESEARCH FINDINGS}

The presentation of the findings starts with commenting on an excerpt (Vignette I) of the team meetings (annotation conventions in the appendix). The team used part of the meeting to discuss a relevant journal paper. More topics were raised in the meetings and reading groups; anyone can propose a paper for discussion and be the moderator.

Vignette I (Episode I): Getting started 
1. Jan ((standing near to the board)) uhm, I'm not sure if it works to have discussions since lot of people haven't read!

2. Francis Let's see!

3. Sheila I tried to read read it, but I didn't understand [((inaudible - background noise of papers, somebody chuckling))]

4. Francis [((inaudible - as above) $)]$

5. Jan Yes actually I was expecting to:: (0.2) have a nice feedback ((smiling))

6. Francis Uh:: I will try (.) no I read it (.) yes not yesterday, but a few years ago heh heh

Jan, who proposed the paper, goes first. He is reminding colleagues of the informal team rules (e.g., coming prepared to the meetings), and it looks like he wants to reproach his colleagues for having disregarded them. His body language is noteworthy: he is standing in front of everyone, close to the board. He is reserving the right to remind colleagues about reciprocal obligations, implying a privileged position. His standing in front of everyone and being the first to take a turn, are associated with the position of a meeting chair. Claiming membership to this category confers a privilege on how to manage this episode, and affects other participants' possibility for action; this kind of power is also called 'epistemic primacy' (Stivers et al., 2011; Heritage and Raymond, 2005). Jan is doing leadership work here; positioning himself as the chair is paving the way for him to lead the discussion.

The following turn is noteworthy: Francis promptly reacts with a 'Let's see', that is dismissing Jan's statement; Francis' reaction could be considered motivating ('do not give up!'). Francis is the first to respond to Jan's comment: his statement is implicitly challenging Jan's right to reprimand the colleagues and thereby his positioning. Sheila reacts by defending herself. She looks at Jan (meaning that she is talking to him); the reason she gives for not being prepared positions her as the student who wants to be diligent, but had an extraordinary task ('I tried to read it, but I didn't understand'). In so doing she accepts Jan's positioning. Francis' next turn is inaudible. Then Jan underlines he was expecting some 'nice feedback'; thus he reasserts his expectations at turn 1 as legitimate, reinforcing his 
positioning. However, he hesitates before stating his expectations, and then he smiles, probably to soften his statement.

Francis' answer (turn 6) is notable: he underlines that he read the paper, even if a few years ago. This shows his long experience, which might position him as the expert in the group; again, this would challenge Jan's positioning as the one who has the right to criticise his colleagues. Though, he is laughing at the end of the sentence, and this looks self-deprecating, he had not come to the meeting prepared. Laughter might look as well as a strategy to downplay the situation, in front of Jan's reassertion of his expectations and therefore his position; downplaying the situation implicitly undermines Jan's claiming of the right to criticise. The meeting continues with Jan taking the initiative to sum up the main points of the paper and write them on the board to facilitate the discussion. Eventually, Jan can build for himself a privileged position: his colleagues do not challenge his right to write on the board, and he can claim for himself a position as a 'lecturer', a position that gives him epistemic primacy.

Jan is using several resources here to work on his positioning. First, he is behaving as if he was the chair; his actions conform to what it is expected from a chair. Second, he strategically uses his knowledge of the group's unwritten norms and his expertise in the topic under discussion. His knowledge and expertise constitute personal resources that enable him to work on his positioning. Furthermore, Francis is using neither his personal nor his social resources to challenge Jan's position; on the contrary, he is using humour, which helps him to make acceptable the fact that he did not prepare for this meeting. This shows that positioning depends on all participants in an interaction. In this episode Jan gained epistemic primacy by positioning himself as a group chair or lecturer would do, but he could do that because the other participants (Francis and Sheila in particular) did not challenge his positioning and recognised his primacy. As argued by Harré and Van Langenhove (1998), positioning one’s 
self and positioning others are two simultaneous processes; also, there is a dynamic of mutual influence between first- and second-order positioning (i.e. positioning one self and others, and questioning first order positioning).

It is important to reflect on this vignette by considering the formal roles of each participant in the group. Jan's first statement might look like the typical assertion of a group chair, however, he is a second-year $\mathrm{PhD}$ student. Francis is the group chair, and he is the only one here (except Jan) to do some significant moves: he minimises Jan's statements, motivates the group to start the discussion, asserts his expertise but also denigrates himself for not having read the paper before the meeting. He might have drawn on more resources to challenge Jan's positioning, however he does not. Sheila is one of the two most advanced $\mathrm{PhD}$ students, but she could not understand the paper.

This vignette tells a few important things about leadership work. This is a work of negotiation that is achieved through a process of reclaiming rights and obligations (and not being challenged); and the strategic mobilisation of knowledge of group norms, and expert knowledge. Leadership work is a dynamic process, which is shaped in each turn; it draws on both emergent and structural resources, and it is closely related to the task at hand. In the case of the vignette above, the fact that most of the participants did not read the paper, represents for Jan an emergent resource to work on his positioning. Then, Jan's use of his subject knowledge represents a structural and personal resource: the use of such knowledge relates to a more stable resource when compared to the unfolding interaction (in fact, it will be demonstrated later on how Jan's subject knowledge becomes a social resource for Jan in this group, since this is regularly recognised as especially relevant by others). It is possible to talk about leadership constellation to indicate how leadership work develops in an episode, this to underline that leadership work is an inherently social phenomenon. The next vignette belongs to the same meeting and shows how this leadership constellation develops. 
Vignette II (Episode I): Getting to the heart of the debate

44. Jan Ok. so (.) I will try to briefly present the main idea and then we will try to discuss it (.) and if you have questions (.) So the idea is very simple (.) right? First they uh they define a cost function (.) right? ((writes on the board)) (0.28) So, ((looking at colleagues)) do you have questions about the cost function?

$(0.2)$

45. Greg ((looks at colleagues)) no.

46. Jan So it's (.) yes, pretty obvious (.) here you have (.) basically this the ((indicating on board)) uh the real cost like processing cost $=$

47. Greg Mm mm

48. Jan $=$ of the (...) resource $>$ so we have the resource time $<$ and this is the:: (.) imaginary cost of retrieval right? This is, related to accuracy, more or less (.) it means that the more relevant documents you retrieve, UH hh yes! here you have + ((continuing to write on the board)) (.) Maybe then $\mathrm{C}+$ should be below 0 (.) or 0 (.) it shouldn't be:: (.) well (.) it should be below 0 (.) Because otherwise retrieving more relevant documents you increase the costs, but you want to minimize the costs. So it was like (.) this really should go down.

Jan gained epistemic primacy, so he is shaping the interaction (turn 44). He is setting expectations and encouraging colleagues to ask questions in an example of performative positioning (Harré and Van Langenhove, 1998). Jan positions himself as a lecturer, and structures the interaction in a predictable way: thus, he explicitly shapes the local moral order. This moral order primarily implies for Jan the right to lead the discussion, but also the obligation to guide his colleagues through the paper by focusing on the relevant points; for Jan's colleagues, the moral order implies the obligation to give Jan attention and the right to make questions (which then should be relevant to the discussed topic). Jan has epistemic primacy here; his colleagues are following him carefully, this strengthening his power position. Jan goes into the details of the paper until Sheila interrupts him with a question. The interaction progresses as follows.

Vignette III (Episode I): A challenging question

49. Sheila Excuse me. but isn't it the cost the retrieval has? So even for relevant retrieval you have a little cost (.) but it's (...)

50. Jan This one ((indicates formula on the board))

51. Sheila No:: that's for something else I guess, that's not for retrieval!

52. Francis That's the cost that uhh you wanna the fact that you access the system, and you spend some time downloading documents.

53. Jan Right.

54. Francis That's it.

55. Sheila Ok. 
56. Francis But the other one is clearly linked on the fact of how many good documents=

57. Sheila Exactly=

58. Francis $=$ You get.

59. Sheila =So I guess even for retrieve for relevant documents we should have a cost, but it's ve::ry

60. Jan It's here ((indicates formula on board)) (.) retrieve $\mathrm{S}$ documents this is the cost of retrieving $\mathrm{S}$ documents. the real cost.

61. Francis (..)

62. Sheila O::k?

63. Jan No no it is by definition (.) this is the cost for retrieving $\mathrm{S}$ documents.

64. Greg It's for query processing (.) fixed costs for query processing.

65. Jan So:: I just cite (.) cost function CIS comprising such factors such as connection time, computation costs, and charges for delivery $>$ for delivery of those documents $<$ so basically (.) they want to separate, the:: uhm computational cost here, ((indicates part of the formula on the board)) and retrieval cost here ((indicates other part of the formula)) (.) so we want to

66. Mat since we want to minimize all [the blocks] $[(\ldots)]$ for the loss.

Sheila's question at turn 49 addresses a point that Jan had not clearly explained; her questions signal her disagreement with Jan. Sheila is reserving the right to contest him. Francis intervenes as well (turns 52 and 56), confirming Sheila's interpretation; between turns 56 and 59, Sheila and Francis complete each other's sentences, indication that their agendas and positions are aligned. Sheila's first intervention at turn 49 , with the subsequent intervention by Francis, seems to challenge the leadership constellation created by Jan's initial positioning, making the conversation more dynamic and collaborative. On the one hand, Jan is still positioning himself as a lecturer (turns $53,60,63,65$ ): he gives prompt answers to the doubts of the colleagues and reserves for him the right to say what is right or wrong. On the other hand, the fact that colleagues (Sheila and Francis) take the turn to explicitly contradict him, signal that they position themselves as peers. Sheila had stated earlier that she had not understood the paper, but her questions at 49 and 51 reveal that she should have mobilised some of her previous knowledge (maybe during the discussion) to make these inferences. Sheila and Francis' interventions represent emergent features of this interaction, because they strictly depend on how the interaction is developing and on Sheila and Francis' interpretation of the topic under discussion (which could not have been predicted by other participants, including Jan). These emergent features are however very important in term of leadership 
work: the fact that both Sheila and Francis clearly disagree with Jan has the potential to challenge Jan's epistemic primacy, thereby reshaping the leadership constellation.

At turn 60 Jan answers by citing part of the formula he had written on the board, as a way to dispel doubts. His proximity to the board means he has better access to some resources (the formula) that are especially relevant at this moment because they give him the epistemic primacy in managing the discussion. In front of Sheila's reaction at 62, Jan quotes a sentence from the paper while indicating the part of the formula he is referring to. Interestingly, Greg's intervention seems to go unnoticed (although he is providing an important part of the answer). At the end Mat also intervenes.

Vignette IV (Episode I): Sorting out doubts

67. Jan Mm?

68. Francis Sorry? (0.3)

69. Mat On the right side you have (the reward) (.) ok? How much you gain uhm from positive erm classification (.) how much you are losing uhm whenever you are returning uhm non relevant documents. and on the left side it's the fixed cost, uhm

70. Greg ((looks at Jan)) are you sure that $\mathrm{C}+$ is less or equal than 0 ?

71. Jan Well, again, if you give, so, you are interested in retrieving relevant documents, right? $\mathrm{C}+$ is the cost for retrieving a relevant document, so, it means that if you retrieve a lot of relevant documents then you increase this cost anyway. But you need to decrease it.

72. Mat Otherwise the optimum will be returning no documents.

73. Jan Yes.

74. Mat So, it's not positive.

75. Greg So, and C - ?

76. Jan C - should be positive.

77. Greg Ok.

Mat wants to clarify some points but he and Jan are talking at the same time. Jan and Francis invite Mat to continue. This regulates the turns and signals that what Mat just said is potentially relevant. At the same time, both Jan and Francis are reserving the right to allocate turns, thereby positioning themselves as co-chairs. Mat continues, then Greg intervenes with a precise question at 70; Jan answers and then Mat completes it, indicating that both Jan and Mat in this moment possess relevant knowledge. At 73, Jan confirms that Mat's intervention is correct, indicating he is reserving for himself the right of establishing what is right and 
wrong, thereby stressing his positioning as a lecturer and carving out epistemic primacy. Greg's questions seem to be directed to Jan (probably because Jan is still standing in front of everyone, confirming his position as a lecturer).

In the last two vignettes, it is possible to observe a transition from a constellation where there is one person only (Jan) who works on a positioning giving him epistemic primacy (being a lecturer), to a dynamic construction of positions achieved through questioning and giving different perspectives on the topic. This dynamic constellation is reached by mobilising expert knowledge, and especially by giving different interpretations (Sheila and Francis), and offering deeper explanations (Mat). It is not clear who is leading the discussion after turn 54 in Vignette III. However, non-verbal communication and Greg's interventions signal that Jan still has the privilege of chairing the conversation: Jan is standing close to the board (that helps him manage the conversation), and questions are addressed to him, this meaning that others are positioning him as if he was the lecturer (accountive positioning). Also, it is important to notice the role played by indexicality, in particular by gestures. Indexicality can be defined as the property of language to point at something, without explicitly mentioning it; for ethnomethodologists, indexicality is part and parcel of talk (Garfinkel, 1967; Rawls, 2008). In this case, Jan seems to be in a privileged position to use indexicality for strengthening his epistemic primacy. Thus, questioning, answering, indicating (i.e. pointing at by means of a gesture) and confirming represent strategic discursive resources: on the one hand, their use is tied to the team's unwritten norms (each team member is expected to participate in the discussion, and turn taking is free); on the other, their enactment depends on individual priorities and interaction styles. For this reason, these discursive resources might be considered as personal resources. The same applies to the activity of allocating turns.

Despite the last two vignettes present a more dynamic leadership constellation, when compared to Vignettes I and II, Jan still positions himself as a lecturer with epistemic 
Vignette V (Episode I): Challenging the agenda

105. Jan Ok (.) so:: we have the cost function that we want to minimi::ze (.) and we have a constraint about this. it means that, we use Lagrange multipliers, $>$ doesn't matter what it is $<$ but it's used when we want to minimize and we:: have additional constraints. and it works like, written in the paper, we we take uhm well. derivative ((writes on the board)) (0.6) of Lagrange multipliers a::nd what we have, is that (.) ((continues to write)) all function derivatives (.)

106. Mat Can I explain about Lagrange multipliers?

107. Jan ${ }^{\circ}$ Yes. $^{\circ}$

Jan continues to explain the details of the paper, similarly to Vignette II. In the middle of turn 105, he mentions 'Lagrange multipliers,' and states that it is not important to know about this. He assumes that his colleagues are unfamiliar with this method and, crucially, he is taking the right to say this is not worth explaining. This is notable: he is deciding which knowledge is worth sharing, and again asserting his primacy. However, Mat politely asks if he can explain the method. On the one hand, Mat's polite question seems to recognise Jan's position as a lecturer. On the other hand, Mat's question challenges Jan's agenda. This also shows Mat's expertise and his willingness to share it; again, expert knowledge seems the most important resource to work on positioning. Jan responds with a simple 'Yes': he renounces bringing further arguments and leaves the floor to Mat. Mat starts explaining the method (see below).

Vignette VI (Episode I): Explaining a new method.

108. Mat The idea is you have (hh) you have an objective function, ((indicates the board)) it maximizes $\mathrm{M}$ or $\mathrm{N}$ (.) uhm and you have a constraint that, all of S (.) Is ${ }^{\circ}$ should be SI in ECI ${ }^{\circ}$ right? (.) They have to sum to M. ok? You have to put that information into the constraint, into your loss 
function (.) how you are gonna do that. Well. if you do if you write M minus the sum of that SI is gonna be equal 0 , right?

109. Greg [yes]

110. Paris [yes]

111. Mat Ok? So if you put. uhm so we add to the loss function (...) the loss function ((goes to the board

- background noise))

112. Jan Can I write?

113. Mat Yes. you can write (.) Lambda (.hh) times something that estimates necessarily equal to 0 (.) ok? ${ }^{\circ}$ if it's not equal to 0 we get in trouble ${ }^{\circ}$ (.) and then we take the derivative of that instead of taking the derivative of the original loss function. it would be better (...) extra information in. [ok?]

114. Sheila [I] didn't understand why we should have that one.

115. Greg (looks at the board) ah ok.

116. Francis Why (...)?

117. Mat U(.hh) $\mathrm{m}$

118. Sheila I didn't understand the second part of that formula, you just add

119. Mat When you are doing a search in a different place, instead of searching now over SI we gonna search over SI and lambda, ok? ((writes on the board)), for the solution, and ignoring that, if we can find the value for lambda, and the value for all the SI, ok? that maximes that equation, ok, it will be the optimum solution for SI, including the constrain that all the SI have to sum to N, ok? So we get an extra variable, lambda, which allows to make sure that the constraint holds.

Mat's colleagues are following him, implicitly confirming that they accept the new positioning. Jan leaves the floor to him and even offers his support (turn 112); this means reshaping the moral order (from the obligation to 'teach' to his colleagues, to the one of supporting Mat's explanation). Consequently, Jan is stepping back from his position as a lecturer. Mat looks like he now has epistemic primacy: his expertise is recognised as relevant, and the episode continues with questions addressed to him and to which he provides detailed answers.

This vignette shows the fluidity of a leadership constellation. In this case the constellation has been reworked explicitly and quickly, with Mat challenging Jan's agenda with a specific question. Leadership work is emergent here: Jan's comment on Lagrange multipliers offers Mat the opportunity to step in; then, all the other participants (Jan included) align themselves to the new leadership constellation. Other developments might have been possible. Again, emergent and structural features come together in defining everyone's positions. Mat is here using two important resources: 1) his expert knowledge (he and Jan seem to be the only ones familiar with Lagrange multipliers); and 2) his special position in the group. Team members 
have a high regard for Mat, because he is always eager to share his expertise and support his junior colleagues; this might explain why nobody challenged Mat's decision to explain a method that Jan dismissed as unimportant.

All six vignettes are part of an episode that will be called 'Scientific debate'. Jan is introducing and discussing a paper that he had proposed. He positions himself as a chair and a lecturer, again gaining epistemic primacy; then, Mat challenges his agenda, positioning himself as a lecturer. Working on a position that allows achieving epistemic primacy seems essential to be able to shape the meeting and influence other people; these behaviours are associated with leadership. The rights and obligations that have been invoked in the positioning processes, paving the way for epistemic primacy, are related to enacting specific knowledge and expertise more than covering formal roles. This means that disciplinary knowledge and expertise in this team are especially important; they permit the team to perform their core tasks and build their reputation.

When considering the entire episode, it is possible to notice how positioning helps to create a storyline, i.e. more stable identities and patterns of interaction in the team. For example, disciplinary knowledge is important for Jan to take the lead in Vignettes I and II, and again in Vignette V, when Mat challenges Jan's agenda. In this team people often consult Jan when a strong background in mathematics is required (as shown in this Episode); this means that Jan's personal resource became for him a social resource, since this is giving him the role of the expert in the field. It was also mentioned that Mat is highly respected by the team, and he is often considered an advisor and mentor. Jan and Mat could build these identities by positioning themselves during team meetings. Moreover, the preferred positioning strategies and interaction styles during the meetings (free turn taking, high participation and possibility to shape the agenda) are also part of a storyline: these patterns were motivated by the group chair, but they have also been actively enacted by the other participants, who used them to 
make their own contribution. The way leadership work is conducted here (e.g., by mobilising resources related to disciplinary knowledge) looks especially functional in this team; consequently, this created for the team a history in which the mobilisation of disciplinary knowledge itself has a privileged role. As a result, positioning strategies that challenge leadership through the use of relevant knowledge became acceptable.

Critics might claim that such fluid leadership work can be easily found in general discussions about topics that do not hold any potential for challenging formal arrangements (Learmonth, 2017). Nevertheless, in this team it was possible to observe interesting moments of leadership work when decisions having a stronger impact on the team everyday life are being taken. The next vignette is part of a long episode on how to create guest accounts for visiting scholars. This episode is called 'Team logistics.'

Vignette VII (Episode II): Team logistics

219. Mat (...) faster for us to do, because we don't have to go through Ivy ((referring to the IT manager)) all the time, and waiting $[(\ldots)]$

220. Nick $\quad[$ (whenever we want $)]=$

221. Francis But

222. Nick =create a new account, remove anything, whatever, we should ask Ivy.

223. Greg Yes, that's:: that also will be, boring, sometimes.

224. Francis I mean, we have to go through Ivy for almost everything, and also we are talking, guests, people, you know, we have three people per year?

225. Nick Yes, that's the point, if we have a guest account. that, because we have three guests per year, that doesn't make that much work, that's not the problem, that somebody leaves data (...) and so, and somebody, somebody else comes and $(\ldots)=$

226. Greg Yes, the only=

227. Nick =we have only two or three per year, so somebody comes and leaves, and after three months, somebody else, you ask the other one, ok. delete the account.

228. Greg =the only problem I can see, is in the case of Maya and Lara, they were both

229. Nick Yes. we can ask for example two or three guest accounts (.) just in case.

230. Mat I don't think people will really, keeping stuff as personal on (...) anyway, uh if you just (...) access to that account (.) when they leave, if they don't need any more, you change the password. and delete whatever they have

231. Francis $\mathrm{Mm}$

232. Mat I mean, (...) we can't see into an account that somebody (...) (.) maybe it's better to go through Ivy, but I think if you add the, access, if you always go through Ivy it won't get done, because $=$

233. Francis No

234. Mat =no, she's good, but then we have to think, uh, we will gonna do that, I'm gonna delete, $>$ the only time we are going worrying about deleting is when we are running out of $\mathrm{sp}(\mathrm{hh})$ ace on the disk $<$ urgent message to Ivy, can you delete this quickly? And then (...) to work out what was, yes. I just see it as an extra level bureaucracy (...)

(ongoing discussion - 5.30 minutes) 
The team usually has two or three visiting scholars per year, who might stay on average 2-4 months and have access to the university facilities. Guest accounts are usually managed centrally in the university, but more team members, Nick and Mat especially (Nick is the most advanced of the $\mathrm{PhD}$ students) would prefer the team to have a few generic guest accounts assigned, and then manage them on an ad-hoc basis. Francis is not in favour of this option, but the discussion continues for a long time. At turn 232, Mat even says that if they have to ask the IT manager, it will not get done (this being an exaggeration, even if during the fieldwork it has been observed that IT staff have been quite slow in addressing some issues). In Vignette VII, both Mat and Nick reclaim for themselves the right to have a special voice in this process: they rely on a breadth of arguments, showing knowledge of university practices and routines. This contextual knowledge is necessary for them to be able to raise more arguments, and to show they would be able to perform the task. Mat and Nick position themselves as if they were actual team leaders, and are leading the discussion, which continues for about five minutes until Francis raises some new arguments (see below).

Vignette VIII (Episode II): The successful argument

286. Francis Bureaucracy is the::re, but $>$ you know $<\mathrm{I}$ have, uhh if we have a guest account, then somebody will have to manage $>$ you know $<$ here comes the person, who should I ask? Who can remember the guest password? (.) You know, I ask him ((indicates Greg)), oh no! maybe it was Nick who did it last time, oh, Nick is not around. uhm:: she is always there $>$ you know $<$ if she is there, and I phone her, and, and she doesn't a thing within a couple of hours, I can complain to somebody. if I ask Greg, he says, oh, Nick has the password for the last guest, you know heh heh

287. ((everybody laughing))

288. Greg Maybe it was Mat ((smiling))

289. Francis It's a different thing, yes, ok? So, anyway, uhh:: I mean, if you have suggestions like creating the index, or maybe creating $>$ you know $<$ a guest for very short time guests and so on, with a password, you know, we ca::n, ${ }^{\circ}$ that's kind of dangerous ${ }^{\circ}$, password guest maybe going around, a::nd, we don't know who is responsible, uh it would be better to call it Nick's guest ((smiling)), then I know if the guest is not there, you can go to Nick, you know, heh heh, but, if you have a guest and that's nobody responsibility to remember the password, to clean it, or everybody responsibility, which is even worst, uh! where's the stuff of the guest? Oh! Nick deleted! Oh! well, you know $>$ the guest told me not to delete it and I forgot to tell Nick! $<$ yes 
Francis stresses that if things do not get done in the IT department, he can pick up his phone and complain (turn 286). This is where the power of his formal role emerges. After more than eight minutes of arguing, Francis get the team to agree: he invents a scenario where the team member who is managing the accounts is not there, or the guest's files have been deleted even if the guest asked to keep them, resulting in total confusion. Francis' non-verbal communication is remarkable. He is mimicking the scene as if he was an actor, changing his intonation and making faces that elicit laughter. This strategy seems more effective than a string of arguments. Francis enacts his authority in an unusual way, and shows the breadth of strategies formal leaders can use to work on their position. It is notable that a small decision requires a disproportionate amount of time and effort since the course of action privileged by the formal leader is constantly being challenged by Mat and Nick's positioning strategies. Francis works hard on his positioning, by bringing in his formal power, but also by improvising a scenario and using humour and laughter. The range of resources mobilised by Nick and Mat have the potential to attempt to the formal order (here represented not only by Francis, but also by the 'bureaucracy', the rules of the university in relation to accessing the IT system).

This episode, 'Team logistics', illustrates two important points on leadership work. First, leadership work has the power to challenge formal roles: Mat and Nick position themselves as if they were co-leaders by using their knowledge of the local context; their position is contrasted by Francis only, who is also reserving for him the right of having a voice. Interestingly, Francis reminds his formal role in an indirect manner (by making participants notice his formal power in the university), and then uses humour and laughter, strategy which successfully allows him to have his option approved. This brings to the second point: leadership work depends on a very broad range of resources, and the ability to mobilise the one which is more relevant in a specific situation becomes key to gain epistemic primacy. It 
is possible that, if the formal chair was not able to work on his positioning, team members could have decided to follow their preferred course of action. As a result, parallel and hidden process might have been created, circumventing and challenging (at least informally) institutional policies and procedures.

\section{Summary of the results}

In this section, four vignettes have been analysed. While the first six (part of 'Scientific debate') focused on disciplinary knowledge, the last two (part of 'Team logistics') focused on team routines. Although the topics being addressed are completely different, notable leadership work is being conducted in both, through the reciprocal and dynamic positioning of team members. Two questions guided this study: 1) how positioning processes in team meetings affect leadership work; and 2) which resources are mobilised in the positioning processes that characterise leadership work.

In relation to the first question, the paper illustrates the following points. First, both performative and accountive positioning contribute to what has been referred to as epistemic primacy: this is a power position, which gives a special privilege in shaping the local moral order; since the moral order is composed of peculiar dynamics of right and obligations, this affects the leadership constellation. It is possible to suggest that positioning impacts leadership work when it implies a negotiation of epistemic primacy, which resettles the local moral order. In the team meetings here analysed, working on a positioning as a lecturer means gaining epistemic primacy. In any case, gaining epistemic primacy is always a momentary accomplishment, as noted in Vignettes III and V.

Second, positioning works through both verbal and non-verbal communication. Body language and laughter are integral to the positioning process. Indexicality, and the negotiation around objects (such as the formula on the board) are also central in leadership work; their 
presence alone affects how epistemic primacy is negotiated, and they are part and parcel of the process (as noted in Vignette III).

Third, positioning affects leadership work whether it is intentional or not. In Vignette III, a question by Sheila opened the possibility for the leadership constellation to be reworked, and this happened even if it is likely that Sheila was not aware of the potential effects of her sentence when she said it. This means that even unintentional acts might play an important part in the processes characterising an organisation.

Fourth, positioning creates a history in and across episodes, where a participant can incrementally build a privileged power position. This allows a reshaping of the local moral order and eventually the leadership constellation (Vignettes I and II). In addition, recurrent positioning strategies might contribute to the shaping of some identities, and become social resources for the participants (as Mat did).

In relation to the resources being mobilised to work on positioning, we notice here the importance of personal resources, especially of knowledge and expertise; this might be disciplinary knowledge, or knowledge of local practices. It is possible to speculate that in different contexts power positions might be built because of factors other than knowledge and expertise. Social resources, such as formal roles, might be used as well: this was observed in 'Team logistics,' when Francis stresses that if things do not get done he can 'pick up the phone and complain'. Other than that, Francis mobilises a personal resource which might look unusual in this context - his sense of humour - to win approval for his preferred course of action.

Importantly, each participant can decide which resources to mobilise: in Vignette I, Francis decides not to use his formal role or disciplinary knowledge. It has also been observed that the link between the use of personal vis-à-vis social resources when doing positioning is quite 
weak. Even if we were able to know which resources each participant has, it is impossible to predict which ones will be mobilised and when.

[Table I (Summary of the Potential Resources to Work on Positioning) above here]

\section{DISCUSSION AND CONCLUSION}

This paper investigated how members of a team shape their leadership constellation, through a dynamic work of positioning and claiming epistemic primacy. Like Choi and Schnurr (2014) and Smith et al. (2017), it shows the unpredictability and fluidity of leadership work. However, the team analysed here has a formal structure (Francis is the group chair, the dissertation supervisor of the $\mathrm{PhD}$ students and the line manager of the post docs), but this does not hinder the creation of fluid leadership constellations. This point provides a strong background to the claim that leadership work is highly fluid and unpredictable. Choi and Schnurr (2014) and Smith et al. (2017) insist that there is some relation between the emergent nature of leadership and some practices or roles coming from the broader institutional environment, but this is not further elaborated. The focus on positioning better sheds some light on this point, by looking for the resources people use when doing leadership work, and observing how use of resources and emergent interaction influence each other. This paper considered not only the discursive resources, as Clifton (2014) did, but applied a broader lens to find a variety of personal and social resources (table I). Clifton $(2014,2017)$ claims that some discursive resources might be tied to specific identities; however, this claim does not seem to hold in this study (but this might be due to the peculiarity of the team, which is characterised by very informal relationships). An important point is that resources change as individuals themselves change and reshape their resources depending on the storyline that the team is developing. This means that the way people work on their and others' positioning, 
dynamically contributes to refine resources. For example, the work to position one's self as a lecturer might require refining the use of some personal resources (e.g., disciplinary knowledge or rhetorical skills), to be capable of shaping the interaction in future circumstances.

This paper adds important evidence to the literature in three ways: (1) by shedding light on how positioning processes might allow accessing epistemic primacy which is key in shaping the leadership constellation; (2) by drawing attention to the resources that can be mobilised to work on positioning, and how recurrent positioning processes feed back into the resources themselves; and (3) by showing that body language and indexicality are part and parcel of positioning processes, and therefore influence the leadership constellation.

This paper should have contributed to relate broader conceptual issues in the study of leadership, such as the relation between emergent interaction and more stable arrangements (such as formal roles) to the empirical analysis of how leadership happens in situ, as auspicated by Larsson (2016). Also, it responds to Schnurr and Schroeder (2018) call to integrate studies of language with studies of leadership. Schnurr and Schroeder argue that ethnomethodology, applied linguistics and pragmatics can provide a very useful standpoint to analyse leadership as it happens; they state that this should help overcoming debates over terminology, and gathering new evidence about the "actual practice(s) of leadership" (Schnurr and Schroeder, 2018: 9). As stressed above, the aim of this paper was to investigate leadership work by giving priority at what happens in interactions first. Ethnomethodology and positioning theory supported the analysis, by directing the attention to how the participants in the interactions made sense of their own role, and shaped theirs and others' position in order to progress with their activities. In absence of a close attention to unfolding interactions first, it would have been impossible to: understand that leadership work is shaped through a subtle work of positioning (i.e. negotiating rights and obligations); realise that 
leadership work is at the same time dependent on emergent interactions and more stable arrangements; observe how people mobilise their resources in order to work on leadership; appreciate that leadership work is an ever-unfolding process, independent of formal roles.

This study presents some limits. In particular, a limit is represented by its focus on one case and site of interaction only (i.e. a specific research group and its team meetings). It might be argued that processes of leadership work might be very different in other institutional contexts (or in other sites of the same institution). Interestingly, most of the research showing the unpredictability of leadership work (Choi and Schnurr, 2014; Smith et al., 2017), relies on data coming from the research and development sector. However, this limit does not refute the point in relation to the benefits of conducting an analysis of positioning. Further research could compare how the same people mobilise their resources across more sites of interaction; this should shed some light not only on how social and personal resources affect other when doing leadership, but also on how local leadership work can challenge more stable institutional processes. 


\section{REFERENCES}

Alvesson M. (2017) Waiting for Godot: Eight major problems in the odd field of leadership studies. Leadership: 1742715017736707.

Alvesson M and Kärreman D. (2000) Varieties of discourse: On the study of organizations through discourse analysis. Human Relations 53: 1125-1149.

Alvesson M and Sveningsson S. (2003a) The great disappearing act: difficulties in doing "leadership". Leadership Quarterly 14: 359-381.

Alvesson M and Sveningsson S. (2003b) Managers doing leadership: The extraordinarization of the mundane. Human Relations 56: 1435-1459.

Asmuß B and Svennevig J. (2009) Meeting talk. Journal of Business Communication 46: 322.

Bamberg M and Georgakopoulou A. (2008) Small stories as a new perspective in narrative and identity analysis. Text \& Talk 28: 377-396.

Bamberg MG. (1997) Positioning between structure and performance. Journal of narrative and life history 7: 335-342.

Barge K and Fairhurst GT. (2008) Living leadership: A systemic constructionist approach. Leadership 4: 227-251.

Boden D. (1994) The business of talk: Organizations in action, Cambridge: Polity Press.

Boden D and Zimmerman DH. (1991) Talk \& social structure, Cambridge: Polity Press.

Carroll B, Levy L and Richmond D. (2008) Leadership as Practice: Challenging the Competency Paradigm. Leadership 4: 363-379.

Choi S and Schnurr S. (2014) Exploring distributed leadership: Solving disagreements and negotiating consensus in a 'leaderless' team. Discourse Studies 16: 3-24.

Clifton J. (2006) A Conversation Analytical Approach to Business Communication. The Case of Leadership. Journal of Business Communication 43: 202-219.

Clifton J. (2012) A discursive approach to leadership: Doing assessments and managing organizational meanings. Journal of Business Communication 49: 148-168.

Clifton J. (2014) Small stories, positioning, and the discursive construction of leader identity in business meetings. Leadership 10: 99-117.

Clifton J. (2017) Taking the (Heroic) Leader Out of Leadership. The In Situ Practice of Distributed Leadership in Decision-Making Talk. In: Ilie C and Schnurr S (eds) Challenging Leadership Stereotypes through Discourse. Singapore: Springer Nature, 45-68.

Collinson D. (2005) Dialectics of leadership. Human Relations 58: 1419-1442.

Crevani L. (2018) Is there leadership in a fluid world? Exploring the ongoing production of direction in organizing. Leadership 14: 1742715015616667.

Davies B and Harré R. (1990) Positioning: the discursive production of selves. Journal for the Theory of Social Behaviour 20: 43-63.

Denis JL, Langley A and Rouleau L. (2010) The Practice of Leadership in the Messy World of Organizations. Leadership 6: 67-88.

Deppermann A. (2015) Positioning. The handbook of narrative analysis: 369-387.

Drew P and Heritage J. (1992) Analyzing talk at work: An introduction. In: Drew P and Heritage J (eds) Talk at work. Interaction in institutional settings. Cambridge:

Cambridge University Press, 3-65.

Edwards D and Potter J. (1992) Discursive psychology, London: Sage.

Eisenhardt KM. (1989) Building theories from case study research. Academy of Management Review 14: 532-550.

Fairhurst GT. (2007) Discursive leadership: In conversation with leadership psychology, London: Sage Publications. 
Fairhurst GT. (2008) Discursive leadership: A communication alternative to leadership psychology. Management Communication Quarterly 21: 510-521.

Fairhurst GT. (2011) Discursive approaches to leadership. In: Bryman A, Collinson D, Grint K, et al. (eds) Tha Sage handbook of leadership. London: Sage, 495-507.

Fairhurst GT and Connaughton SL. (2014) Leadership: A communicative perspective. Leadership 10: 7-35.

Fairhurst GT and Uhl-Bien M. (2012) Organizational discourse analysis (ODA): Examining leadership as a relational process. Leadership Quarterly 23: 1043-1062.

Garfinkel H. (1967) Studies in ethnomethodology, Englewood Cliffs, NJ: Prentice Hall.

Gronn P. (2000) Distributed properties: A new architecture for leadership. Educational management \& administration 28: 317-338.

Gronn P. (2002) Distributed leadership as a unit of analysis. The Leadership Quarterly 13: 423-451.

Harré R, Moghaddam FM, Cairnie TP, et al. (2009) Recent Advances in Positioning Theory. Theory \& Psychology 19: 5-31.

Harré R and Van Langenhove L. (1998) Positioning theory: Moral contexts of international action: Wiley-Blackwell.

Heritage J and Clayman S. (2011) Talk in action: Interactions, identities, and institutions, Chichester, West Sussex: John Wiley \& Sons.

Heritage J and Raymond G. (2005) The terms of agreement: Indexing epistemic authority and subordination in talk-in-interaction. Social psychology quarterly 68: 15-38.

Hirvonen P. (2016) Positioning theory and small-group interaction: Social and task positioning in the context of joint decision-making. Sage Open 6: 2158244016655584.

Hosking DM. (1988) Organizing, leadership and skilful process. Journal of Management Studies 25: 147-166.

Huisman M. (2001) Decision-making in meetings as talk-in-interaction. International Studies of Management \& Organization 31: 69-90.

Huxham C and Vangen S. (2000) Leadership in the shaping and implementation of collaboration agendas: How things happen in a (not quite) joined-up world. Academy of Management Journal: 1159-1175.

Kelly S. (2008) Leadership: A categorical mistake? Human Relations 61: 763-782.

Kelly S. (2014) Towards a negative ontology of leadership. Human Relations 67: 905-922.

Kelly S, White MI, Martin D, et al. (2006) Leadership refrains: Patterns of leadership. Leadership 2: 181-201.

Larsson M. (2016) Leadership in interaction. In: Storey J, Hartley J, Denis JL, et al. (eds) The Routledge Companion to Leadership. Routledge, 173-193.

Larsson M and Lundholm SE. (2010) Leadership as work-embedded influence: A microdiscursive analysis of an everyday interaction in a bank. Leadership 6: 159-184.

Learmonth M. (2017) Book review: Leadership-as-practice: Theory and application. Management Learning: 1-3.

Rawls AW. (2008) Garfinkel, ethnomethodology, and workplace studies. Organization Studies 29: 701-732.

Robinson VMJ. (2001) Embedding leadership in task performance. In: Wong K-cE, Colin V. (ed) Leadership for quality schooling. London: Routledge/Falmer, 90-102.

Sacks H. (1992) Lectures on Conversation, Oxford: Blackwell.

Sacks H, Schegloff EA and Jefferson G. (1974) A simplest systematics for the organization of turn-taking for conversation. Language 50: 696-735.

Schnurr S and Schroeder A. (2018) A critical reflection of current trends in discourse analytical research on leadership across disciplines. A call for a more engaging dialogue. Leadership: 1742715018767687. 
Schwartzman HB. (1989) The meeting. Gatherings in organizations and communities, New York: Plenum Press.

Smith P, Haslam SA and Nielsen JF. (2017) In Search of Identity Leadership: An ethnographic study of emergent influence in an interorganizational R\&D team. Organization Studies: 0170840617727781.

Stivers T, Mondada L and Steensig J. (2011) Knowledge, morality and affiliation in social interaction. In: Stivers T, Mondada L and Steensig J (eds) The morality of knowledge in conversation. Cambridge: Cambridge University Press, 3-24.

Stokoe E. (2012) Moving forward with membership categorization analysis: Methods for systematic analysis. Discourse Studies 14: 277-303.

Sutherland N. (2016) Investigating leadership ethnographically: Opportunities and potentialities. Leadership: 1742715016676446.

Svennevig J. (2008) Exploring leadership conversations. Management Communication Quarterly 21: 529-536.

Svennevig J. (2012) Interaction in workplace meetings. Discourse Studies 14: 3-10.

Tourish D. (2014) Leadership, more or less? A processual, communication perspective on the role of agency in leadership theory. Leadership 10: 79-98.

Uhl-Bien M. (2006) Relational Leadership Theory: Exploring the social processes of leadership and organizing. Leadership Quarterly 17: 654-676.

Van De Mieroop D and Schnurr S. (2014) Negotiating meaning and co-constructing institutionalisable answers: Leadership through gate-keeping in performance appraisal interviews. Journal of Pragmatics 67: 1-16.

Vine B, Holmes J, Marra M, et al. (2008) Exploring co-leadership talk through interactional sociolinguistics. Leadership 4: 339-360.

Wiggins S and Potter J. (2008) Discursive psychology. In: Willig C and Stainton-Rogers W (eds) The Sage handbook of qualitative research in psychology. London: Sage, 73-90.

Wood M and Ladkin D. (2008) The Event's the Thing: Brief Encounters With the Leaderful Moment. In: James KT and Collins J (eds) Leadership Perspectives: Knowledge into Action. London: Palgrave Macmillan UK, 15-28.

Yukl G. (1999) An evaluation of conceptual weaknesses in transformational and charismatic leadership theories. The Leadership Quarterly 10: 285-305. 
Alvesson M. (2017) Waiting for Godot: Eight major problems in the odd field of leadership studies. Leadership: 1742715017736707.

Alvesson M and Kärreman D. (2000) Varieties of discourse: On the study of organizations through discourse analysis. Human Relations 53: 1125-1149.

Alvesson M and Sveningsson S. (2003a) The great disappearing act: difficulties in doing "leadership". Leadership Quarterly 14: 359-381.

Alvesson M and Sveningsson S. (2003b) Managers doing leadership: The extraordinarization of the mundane. Human Relations 56: 1435-1459.

Asmuß B and Svennevig J. (2009) Meeting talk. Journal of Business Communication 46: 322.

Bamberg M and Georgakopoulou A. (2008) Small stories as a new perspective in narrative and identity analysis. Text \& Talk 28: 377-396.

Bamberg MG. (1997) Positioning between structure and performance. Journal of narrative and life history 7: 335-342.

Barge K and Fairhurst GT. (2008) Living leadership: A systemic constructionist approach. Leadership 4: 227-251.

Boden D. (1994) The business of talk: Organizations in action, Cambridge: Polity Press.

Boden D and Zimmerman DH. (1991) Talk \& social structure, Cambridge: Polity Press.

Carroll B, Levy L and Richmond D. (2008) Leadership as Practice: Challenging the Competency Paradigm. Leadership 4: 363-379.

Choi S and Schnurr S. (2014) Exploring distributed leadership: Solving disagreements and negotiating consensus in a 'leaderless' team. Discourse Studies 16: 3-24.

Clifton J. (2006) A Conversation Analytical Approach to Business Communication. The Case of Leadership. Journal of Business Communication 43: 202-219.

Clifton J. (2012) A discursive approach to leadership: Doing assessments and managing organizational meanings. Journal of Business Communication 49: 148-168.

Clifton J. (2014) Small stories, positioning, and the discursive construction of leader identity in business meetings. Leadership 10: 99-117.

Clifton J. (2017) Taking the (Heroic) Leader Out of Leadership. The In Situ Practice of Distributed Leadership in Decision-Making Talk. In: Ilie C and Schnurr S (eds) Challenging Leadership Stereotypes through Discourse. Singapore: Springer Nature, 45-68.

Collinson D. (2005) Dialectics of leadership. Human Relations 58: 1419-1442.

Crevani L. (2018) Is there leadership in a fluid world? Exploring the ongoing production of direction in organizing. Leadership 14: 1742715015616667.

Davies B and Harré R. (1990) Positioning: the discursive production of selves. Journal for the Theory of Social Behaviour 20: 43-63.

Denis JL, Langley A and Rouleau L. (2010) The Practice of Leadership in the Messy World of Organizations. Leadership 6: 67-88.

Deppermann A. (2015) Positioning. The handbook of narrative analysis: 369-387.

Drew P and Heritage J. (1992) Analyzing talk at work: An introduction. In: Drew P and Heritage $\mathrm{J}$ (eds) Talk at work. Interaction in institutional settings. Cambridge: Cambridge University Press, 3-65.

Edwards D and Potter J. (1992) Discursive psychology, London: Sage.

Eisenhardt KM. (1989) Building theories from case study research. Academy of Management Review 14: 532-550.

Fairhurst GT. (2007) Discursive leadership: In conversation with leadership psychology, London: Sage Publications.

Fairhurst GT. (2008) Discursive leadership: A communication alternative to leadership psychology. Management Communication Quarterly 21: 510-521. 
Fairhurst GT. (2011) Discursive approaches to leadership. In: Bryman A, Collinson D, Grint K, et al. (eds) Tha Sage handbook of leadership. London: Sage, 495-507.

Fairhurst GT and Connaughton SL. (2014) Leadership: A communicative perspective. Leadership 10: 7-35.

Fairhurst GT and Uhl-Bien M. (2012) Organizational discourse analysis (ODA): Examining leadership as a relational process. Leadership Quarterly 23: 1043-1062.

Garfinkel H. (1967) Studies in ethnomethodology, Englewood Cliffs, NJ: Prentice Hall.

Gronn P. (2000) Distributed properties: A new architecture for leadership. Educational management \& administration 28: 317-338.

Gronn P. (2002) Distributed leadership as a unit of analysis. The Leadership Quarterly 13: 423-451.

Harré R and Van Langenhove L. (1998) Positioning theory: Moral contexts of international action: Wiley-Blackwell.

Heritage J and Clayman S. (2011) Talk in action: Interactions, identities, and institutions, Chichester, West Sussex: John Wiley \& Sons.

Heritage J and Raymond G. (2005) The terms of agreement: Indexing epistemic authority and subordination in talk-in-interaction. Social psychology quarterly 68: 15-38.

Hirvonen P. (2016) Positioning theory and small-group interaction: Social and task positioning in the context of joint decision-making. Sage Open 6: 2158244016655584.

Hosking DM. (1988) Organizing, leadership and skilful process. Journal of Management Studies 25: 147-166.

Huisman M. (2001) Decision-making in meetings as talk-in-interaction. International Studies of Management \& Organization 31: 69-90.

Huxham C and Vangen S. (2000) Leadership in the shaping and implementation of collaboration agendas: How things happen in a (not quite) joined-up world. Academy of Management Journal: 1159-1175.

Kelly S. (2008) Leadership: A categorical mistake? Human Relations 61: 763-782.

Kelly S. (2014) Towards a negative ontology of leadership. Human Relations 67: 905-922.

Kelly S, White MI, Martin D, et al. (2006) Leadership refrains: Patterns of leadership. Leadership 2: 181-201.

Larsson M. (2016) Leadership in interaction. In: Storey J, Hartley J, Denis JL, et al. (eds) The Routledge Companion to Leadership. Routledge, 173-193.

Larsson M and Lundholm SE. (2010) Leadership as work-embedded influence: A microdiscursive analysis of an everyday interaction in a bank. Leadership 6: 159-184.

Learmonth M. (2017) Book review: Leadership-as-practice: Theory and application. Management Learning: 1-3.

Robinson VMJ. (2001) Embedding leadership in task performance. In: Wong K-cE, Colin V. (ed) Leadership for quality schooling. London: Routledge/Falmer, 90-102.

Sacks H. (1992) Lectures on Conversation, Oxford: Blackwell.

Sacks H, Schegloff EA and Jefferson G. (1974) A simplest systematics for the organization of turn-taking for conversation. Language 50: 696-735.

Schnurr S and Schroeder A. (2018) A critical reflection of current trends in discourse analytical research on leadership across disciplines. A call for a more engaging dialogue. Leadership: 1742715018767687.

Schwartzman HB. (1989) The meeting. Gatherings in organizations and communities, New York: Plenum Press.

Smith P, Haslam SA and Nielsen JF. (2017) In Search of Identity Leadership: An ethnographic study of emergent influence in an interorganizational R\&D team. Organization Studies: 0170840617727781. 
Stivers T, Mondada L and Steensig J. (2011) Knowledge, morality and affiliation in social interaction. In: Stivers T, Mondada L and Steensig J (eds) The morality of knowledge in conversation. Cambridge: Cambridge University Press, 3-24.

Stokoe E. (2012) Moving forward with membership categorization analysis: Methods for systematic analysis. Discourse Studies 14: 277-303.

Sutherland N. (2016) Investigating leadership ethnographically: Opportunities and potentialities. Leadership: 1742715016676446.

Svennevig J. (2008) Exploring leadership conversations. Management Communication Quarterly 21: 529-536.

Svennevig J. (2012) Interaction in workplace meetings. Discourse Studies 14: 3-10.

Tourish D. (2014) Leadership, more or less? A processual, communication perspective on the role of agency in leadership theory. Leadership 10: 79-98.

Uhl-Bien M. (2006) Relational Leadership Theory: Exploring the social processes of leadership and organizing. Leadership Quarterly 17: 654-676.

Van De Mieroop D and Schnurr S. (2014) Negotiating meaning and co-constructing institutionalisable answers: Leadership through gate-keeping in performance appraisal interviews. Journal of Pragmatics 67: 1-16.

Vine B, Holmes J, Marra M, et al. (2008) Exploring co-leadership talk through interactional sociolinguistics. Leadership 4: 339-360.

Wiggins S and Potter J. (2008) Discursive psychology. In: Willig C and Stainton-Rogers W (eds) The Sage handbook of qualitative research in psychology. London: Sage, 73-90.

Wood M and Ladkin D. (2008) The Event's the Thing: Brief Encounters With the Leaderful Moment. In: James KT and Collins J (eds) Leadership Perspectives: Knowledge into Action. London: Palgrave Macmillan UK, 15-28.

Yukl G. (1999) An evaluation of conceptual weaknesses in transformational and charismatic leadership theories. The Leadership Quarterly 10: 285-305. 
APPENDIX

\section{Annotation conventions}

\begin{tabular}{ll}
\hline Symbol & Meaning \\
\hline$\cdot$ & Falling intonation \\
, & Temporary falling intonation \\
$?$ & Rising intonation \\
$!$ & Rising pitch, exclamation \\
$()$. & Micropause (less than 2 seconds) \\
$(0.2)$ & Pause, in seconds \\
$(($ word $))$ & Contextual information \\
$($ word $)$ & Audio not clear \\
{$[$ word] } & Overlapping speech \\
$:$ & Sound stretching \\
$=$ & Latched utterances \\
word & Emphasis \\
WORD & Talking loud, shouting \\
${ }^{\circ}$ word & Softer than surrounding talk \\
$>$ word $<$ & Faster than surrounding talk \\
hh $\quad$ hh & Exhalation / Inhalation \\
Wo(h)rd & Laughter within the talk \\
\hline Adapted from: Jefferson, G. (2004). Glossary of transcript symbols with an introduction. In G. H. Lerner (Ed). \\
Conversation Analysis: Studies from the First Generation. (pp: 13-31). Amsterdam: John Benjamins. \\
\hline
\end{tabular}




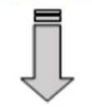

LEADERSHIP WORK

unfolds through

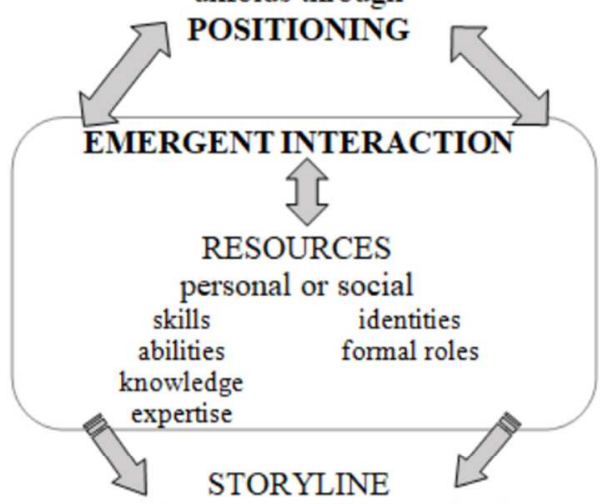

connecting past and future episodes

Conceptual framework 


\section{Transcription of the data}

2. Analysis of each turn (communicative micro event)

10

11

12

13

14

15

16

17

18

19

20

21

22

23

24

25

26

27

28

29

30

31

32

33

34

35

36

37

38

39

40

41

42

43

44

45

46

47

48

49

50

51

52

53

54

55

56

57

58

59

60

Fig II Analytical framework

$303 \times 187 \mathrm{~mm}(96 \times 96$ DPI $)$

ANALYSIS OF

POSITIONING

\section{Analysis of the storyline}

- How is positioning impacting on the construction of a storyline? 


\begin{tabular}{|c|c|c|}
\hline \multicolumn{3}{|c|}{ Personal resources } \\
\hline & \multicolumn{2}{|l|}{ Relevant knowledge } \\
\hline & & Subject knowledge \\
\hline & & Local practices, norms and routines \\
\hline & & Institutional policies and procedures \\
\hline & & Wider community, network (e.g. the academic community in the field) \\
\hline & \multicolumn{2}{|l|}{ Abilities and skills } \\
\hline & & Technical expertise (e.g. specific scientific methods) \\
\hline & & $\begin{array}{l}\text { Sector-specific skills (e.g. academic skills such as publication of papers, } \\
\text { submission of grants, etc.) }\end{array}$ \\
\hline & & Social skills (e.g. interaction styles, teamwork) \\
\hline & & Rhetorical skills (e.g. fluent arguing) \\
\hline & \multicolumn{2}{|c|}{ Discursive resources } \\
\hline & & $\begin{array}{l}\text { Opening, following up (e.g. by questioning or confirming), and closing } \\
\text { conversations }\end{array}$ \\
\hline & & Use of humour, laughter, jokes \\
\hline & & Past anecdotes, team stories \\
\hline & \multicolumn{2}{|c|}{ Non-verbal communication } \\
\hline & & Body language \\
\hline & & Use of space \\
\hline \multicolumn{3}{|c|}{ Social resources } \\
\hline & \multicolumn{2}{|c|}{$\begin{array}{l}\text { Formal roles (as explicitly assigned by an institution and recognised even beyond a specific } \\
\text { workplace) }\end{array}$} \\
\hline & \multicolumn{2}{|c|}{ Social identities (informal roles, shaped by recurrent interaction with colleagues) } \\
\hline
\end{tabular}

